\title{
Associação entre a cargáa viral e os linfócitos T CD4+ com as lesões intra-epiteliais do colo uterino em mulheres infectadas pelo vírus da imunodeficiência humana
}

\author{
Association between viral load and $\mathrm{CD}^{+} \mathrm{T}$ lymphocyte count and cervical \\ intraepithelial lesions in HIV-infected women
}

Angela Cristina Labanca de Araújo므. Victor Hugo de $\mathrm{Melo}^{2}$, Lúcia Porto Fonseca de Castro ${ }^{3}$, Mark Drew Crosland Guimarães ${ }^{4}$, Agdemir Waléria Aleixo ${ }^{5}$, Maria Luiza Silva ${ }^{6}$

\section{RESUM0}

Objetivos: verificar se a contagem de linfócitos T CD4+ e a carga viral do HIV têm influência na presença de lesões intraepiteliais cervicais (SIL). Métodos: estudo transversal, no qual foram selecionadas 134 mulheres HIV-positivas, todas submetidas à biópsia do colo uterino, quantificação da carga viral do HIV e contagem de linfócitos T CD4. Os valores laboratoriais da quantificação da carga viral e da contagem de linfócitos T CD4+ foram obtidos antes da realização da biópsia, tendo sido estabelecidos cortes para o estudo da carga viral ( $\leq 400$ cópias $/ \mathrm{mL} ; 401$ a 50.000 cópias $/ \mathrm{mL} ;>50.000$ cópias $/ \mathrm{mL}$ ) e contagem de linfócitos T CD4 ${ }^{+}\left(<200\right.$ células $/ \mathrm{mm}^{3} ; 200$ a 350 células $/ \mathrm{mm}^{3} ;>350$ células $\left./ \mathrm{mm}^{3}\right)$. Foram realizados os testes $\chi^{2}, \chi^{2}$ de tendência linear, $\chi^{2}$ de Mantel-Haenszel e análise de variância. Estabeleceu-se significância estatística para $\mathrm{p}<0,05$ e intervalo de confiança a 95\%. Resultados: não houve tendência de risco para as mulheres HIV-positivas apresentarem SIL com o aumento da carga viral ou diminuição dos linfócitos T CD4+. Comparando-se a carga viral com a presença ou ausência de SIL, estratificada pelo tempo em que foi quantificada, houve diferença significante para valores acima de 400 cópias/mL (OR: 3,17; IC 95\%: 1,02-9,93; p=0,048). Nenhuma associação foi encontrada para a contagem de linfócitos T CD4+ com a presença da SIL. Conclusão: as pacientes com carga viral do HIV maior que 400 cópias/mL, quantificada antes da biópsia do colo uterino, apresentaram chance 3,17 vezes maior de desencadear SIL. A contagem de linfócitos T CD4+ não influenciou no aparecimento da SIL.

PALAVRAS-CHAVE: Colo uterino/ patologia; Neoplasia intra-epitelial cervical; HIV, Síndrome da imunodeficiência adquirida; Carga viral; Linfócitos T

\section{ABSTRACT}

Purpose: to evaluate $\mathrm{CD}^{+} \mathrm{T}$ lymphocyte cell count and HIV viral load influence on the presence of cervical squamous intraepithelial lesions (SIL). Methods: cross-sectional study of $134 \mathrm{HIV}$-infected women submitted to uterine cervical biopsy, $\mathrm{HIV}$ viral load quantification and $\mathrm{CD}^{+}$T lymphocyte cell count. Viral load and CD4 ${ }^{+} \mathrm{T}$ lymphocyte cell count were performed before biopsy timing. Three different levels of viral load ( $\leq 400$ copies $/ \mathrm{mL} ; 401$ to $50,000 \mathrm{copies} / \mathrm{mL} ;>50,000 \mathrm{copies} / \mathrm{mL}$ ) and $\mathrm{CD}^{+} \mathrm{T}$ lymphocyte count $\left(<200\right.$ cells $/ \mathrm{mm}^{3} ; 200$ to 350 cells $/ \mathrm{mm}^{3} ;>350$ cells $\left./ \mathrm{mm}^{3}\right)$ were defined. Data were statistically analyzed by the $\chi^{2}$ test, linear tendency $\chi^{2}$ test, Mantel-Haenszel test, and analysis of variance, with level of significance set at $\mathrm{p}<0.05$ and $95 \%$ confidence interval. Results: there was no risk tendency for HIV-infected women to show SIL with viral load level increase or $\mathrm{CD}^{+} \mathrm{T}$ lymphocyte reduction. Comparing viral load with the presence or absence of SIL, stratified by quantification timing, there was a significant difference for values over 400 copies/mL ( $\mathrm{p}=0.048$; OR: 3.17; 95\% CI: 1,02-9.93). No association was found between $\mathrm{CD}^{+}{ }^{+} \mathrm{T}$ lymphocyte cell count and SIL. Conclusion: patients with HIV viral load higher than 400 copies/mL, performed before uterine cervical biopsy, showed a 3.17 times greater chance to develop SIL. CD4 ${ }^{+} \mathrm{T}$ lymphocyte count had no influence on the development of SIL.

KEYWORDS: Cervix utery/ pathologgy; Cervical intraepithelial neoplasia; HIV. Acquired immunodeficiency syndrome; Viral load; Lymphocytes

\footnotetext{
Trabalho realizado no Centro de Treinamento e Referências em Doenças Infecciosas e Parasitárias Orestes Diniz (CTR-DIP) 1 Médica da Prefeitura Municipal de Belo Horizonte

2 Professor Adjunto do Departamento de Ginecologia e Obstetrícia da Universidade Federal de Minas Gerais

3 Professora Assistente do Departamento de Anatomia Patológica e Medicina Legal da Faculdade de Medicina da Universidade Federal de Minas Gerais

4 Professor Doutor da Faculdade de Medicina da UFMG.

5 Pesquisadora do Laboratório de Doenças Infecciosas e Parasitárias da Faculdade de Medicina da Universidade Federal de Minas Gerais

6 Farmacêutica Bioquímica do Hospital das Clínicas da Universidade Federal de Minas Gerais

Correspondência: Angela Cristina Labanca de Araújo

Rua Guajajaras 880, sala 1008 - Centro - 30180-100 - Belo Horizonte - MG - Fone: (31) 3201-4194 - e-mail: angelalabanca@shark.com.br

Recebido em: 18/2/2005 Aceito com modificações em: 10/3/2005

Rev Bras Ginecol Obstet. 2005; 27(3): 106-11
} 
Introdução

A relação entre o vírus da imunodeficiência humana (HIV) e a neoplasia do colo uterino foi suspeitada pela primeira vez em $1988^{1}$. Esta associação readquiriu importância no estudo da infecção pelo HIV quando o Centro de Prevenção e Controle de Doenças $(\mathrm{CDC})^{2}$ considerou o carcinoma cervical invasivo como condição indicadora de AIDS, independente do valor da contagem dos linfócitos T $\mathrm{CD}^{+}$. Mulheres infectadas pelo HIV podem ter prevalência dez vezes maior de lesão intra-epitelial escamosa cervical (SIL), quando comparadas a pacientes soronegativas para o $\mathrm{HIV}^{3}$. Isto é relevante em vista do fato de que a infecção por certos tipos do papilomavirus humano (HPV) ter sido vinculada ao desenvolvimento de neoplasia cervical ${ }^{4,5}$, associação já claramente estabelecida ${ }^{6-8}$.

Por outro lado, foi demonstrado que a infecção por genótipos específicos do HPV se associa etiologicamente com SIL e carcinoma cervical invasivo, e a imunossupressão secundária à infecção pelo HIV está associada com a alta prevalência de SIL e alta taxa de persistência destas lesões ${ }^{9}$.

Acredita-se que a prevalência da infecção pelo HPV aumenta à medida que ocorre progressão do dano imunológico associado à infecção pelo HIV, e que a persistência da infecção pelo HPV é inversamente proporcional à contagem de linfócitos $\mathrm{T} \mathrm{CD}^{+}$e diretamente proporcional à carga viral do $\mathrm{HIV}^{10}$.

Com as modernas técnicas de biologia molecular, aplicadas em amostras cervicais, têm sido encontrados múltiplos genótipos do HPV em mulheres imunocomprometidas, não sendo observada associação desses com a classificação citológica ou com os marcadores da infecção pelo HIV, como a carga viral e a contagem de linfócitos T CD4+. Também o número médio de tipos de HPV não aumenta com o agravamento da classificação citológica, ou a diminuição da contagem de linfócitos T CD4 ${ }^{+11,12}$. A carga viral do HIV é marcador útil para a predição da progressão da doença e monitorização da eficácia do tratamento anti-retroviral ${ }^{10-13}$. Tem sido sugerido que a infectividade do HIV é função da concentração do virus $^{14}$. Ainda não está bem claro o mecanismo pelo qual as pacientes com alta carga viral do HIV têm maior comprometimento imunológico. Supõese que a grande quantidade de virus circulante leve a maior replicação viral e, conseqüentemente, mais destruição dos linfócitos T CD4 ${ }^{+15}$.

A terapia anti-retroviral de alta potência (HAART) pode influenciar a relação entre o HIV e os precursores do câncer cervical de duas maneiras diferentes. Primeiro, por prolongar a vida, pode aumentar a duração da exposição ao HPV, desse modo permitindo a acumulação de mutações genéticas somáticas que aumentam a probabilidade de doença cervical. Inversamente, a HAART pode diminuir a carga viral do HIV e restaurar parcialmente a competência imune, atenuando o efeito do HIV no curso da doença pelo HPV ${ }^{16}$.

Tem sido demonstrada a associação entre a carga viral do HIV e o grau de SIL no exame citopatológico, com tendência a maior grau de SIL nas pacientes com maior carga viral do HIV. Por outro lado, ainda não está estabelecida a associação entre o diagnóstico histopatológico dos diferentes graus de SIL e a contagem de linfócitos $\mathrm{T}$ $\mathrm{CD}^{+}$. Da mesma forma, não há evidência de associação entre o laudo histopatológico e a carga viral do HIV ${ }^{17}$.

O objetivo deste estudo foi avaliar se a carga viral do HIV e a contagem de linfócitos $\mathrm{T} \mathrm{CD} 4^{+}$têm influência na presença das lesões intra-epiteliais cervicais diagnosticadas pelo exame histopatológico em grupo de mulheres infectadas pelo HIV, acompanhadas em ambulatório de referência para doenças infecciosas.

\section{Pacientes e Métodos}

Estudo transversal, retrospectivo, envolvendo pacientes atendidas no período de abril de 1997 a maio de 2003 no Ambulatório de Ginecologia do Centro de Treinamento e Referências em Doenças Infecciosas e Parasitárias Orestes Diniz (CTRDIP) da Prefeitura Municipal de Belo Horizonte, em convênio com a Faculdade de Medicina e o Hospital das Clínicas da Universidade Federal de Minas Gerais (HC-UFMG).

Foram selecionadas 134 pacientes HIV-positivas submetidas à biópsia do colo uterino devido à alteração ao exame colposcópico. Todas deveriam estar em uso de anti-retrovirais na data da biópsia e ter pelo menos uma quantificação da carga viral do HIV ou uma contagem de linfócitos T $\mathrm{CD}^{+}$, ou ambas, até a data da realização da biópsia do colo uterino. Se a paciente apresentasse mais de uma quantificação da carga viral do HIV ou contagem de linfócitos $\mathrm{T} \mathrm{CD}^{+}$, utilizar-se-iam, para a presente análise, os valores mais antigos.

Para aquelas que tinham mais de uma biópsia do colo uterino, realizada em momentos diferentes, foi selecionada aquela com resultado mais grave. Caso houvesse resultados iguais, seria selecionado o mais recente. Foi considerada 
portadora da doença em estudo a paciente com laudo histopatológico positivo para displasia cervical/SIL de qualquer grau (LSIL ou HSIL). As que apresentaram biópsias do colo uterino sem alterações, cervicite de qualquer grau e/ou positivas para HPV, desde que negativas para displasia cervical/SIL de qualquer grau, foram consideradas não portadoras do evento em estudo.

Todas as pacientes foram submetidas à coleta de material para citologia oncótica cervical com espátula de Ayre, escova endocervical e biópsia do colo uterino das áreas com colposcopia alterada. Foi utilizado o colposcópio marca Leisegang, com um aumento, e pinça de biópsia Gaylor-Medina. O material biopsiado foi revisado por uma única patologista. As lâminas foram coradas com hematoxilina-eosina, examinadas em microscópio binocular, marca Leica, modelo DMLB, de três cabeças. A análise e a descrição histopatológica seguiram as orientações de Wright et al. ${ }^{18}$, baseadas na classificação proposta por Richart ${ }^{19}$.

A carga viral foi quantificada pelos testes Nuclisens HIV-1 RNA QT, tecnologia NASBA, técnica que amplifica os ácidos nucléicos baseada em seqüência (Organon Teknika, Turnhout, Belgium) e Quantiplex HIV RNA 3.0, tecnologia bDNA, técnica que utiliza moléculas de DNA ramificadas (Bayer System 340 bDNA Analyser, New York, USA). A contagem de linfócitos $\mathrm{T} \mathrm{CD}^{+}$foi realizada pela citometria de fluxo, técnica que utiliza anticorpos monoclonais e fornece a contagem absoluta pela emissão de luz (Becton Dickinson, Immunocytometry Systems, San José, CA, USA).

A carga viral foi estudada em três cortes: $\leq 400$ cópias / mL; de 401 a 50.000 cópias / mL e >50.000 cópias /mL. Esta escolha baseou-se na observação do valor que representa o limite inferior de detecção dos testes disponiveis para a quantificação da carga viral e o valor que supostamente, sem levar em consideração outros fatores, pode-se considerar progressão da doença causada pelo HIV. Os cortes estabelecidos para as categorias da contagem de linfócitos $\mathrm{T} \mathrm{CD}^{+}$foram baseados nas recomendações do Ministério da Saúde para o uso da terapia anti-retroviral em adultos e adolescentes infectados pelo HIV: $<200$ células $/ \mathrm{mm}^{3}$, de 200 a 350 células / $\mathrm{mm}^{3}$ e $>350$ células $/ \mathrm{mm}^{3}$. Para os dois exames estratificou-se pela data de realização dos mesmos em $\leq 6$ meses e $>6$ meses.

Foi utilizado o teste $\chi^{2}$ de tendência linear para avaliar se havia tendência de risco para SIL à medida que a carga viral aumentasse ou a contagem de linfócitos T $\mathrm{CD}^{+}{ }^{+}$diminuísse ${ }^{20}$. A associação entre carga viral do HIV e presença de SIL, controlada pelo tempo da realização do exame, foi avaliada pelo método de Mantel-Haenszel. O risco foi estimado pelo odds ratio com intervalo de confiança a 95\%. O mesmo procedimento foi utilizado para esta análise com a contagem de linfócitos $\mathrm{T}$ $\mathrm{CD}^{+21}$. Foi utilizada a análise de variância oneway (ANOVA) para comparar se o valor médio da carga viral e linfócitos $\mathrm{T} \mathrm{CD} 4^{+}$era afetado pela classificação dos grupos (presença ou ausência de SIL).

O projeto foi aprovado pelo Comitê de Ética em Pesquisa da Universidade Federal de Minas Gerais, juntamente com o termo de consentimento livre e esclarecido, assinado pelas pacientes e pesquisadores.

\section{Resultados}

Foram estudadas 134 pacientes portadoras do HIV, em uso de uma ou mais drogas antiretrovirais, independente do tempo de uso, até a data da biópsia do colo uterino. Destas, 69 (51,5\%) apresentaram algum grau de SIL no diagnóstico histopatológico e $65(48,5 \%)$ foram negativas para SIL. A idade do grupo variou de 17 a 64 anos, com mediana de 32 anos e média de $32,4 \pm 7,8$ anos.

Para avaliar se havia maior tendência de aparecimento da SIL, à medida que aumentava a carga viral ou a contagem de linfócitos $\mathrm{T} \mathrm{CD} 4^{+}$era reduzida, foi utilizado o $\chi^{2}$ de tendência linear ${ }^{20}$. Para a carga viral o resultado do teste não foi significante $(p=0,059)$ mas, indicando que pode haver maior tendência de aparecimento da SIL à medida que aumenta a carga viral. Para a contagem de linfócitos $\mathrm{T} \mathrm{CD}^{+}$não houve diferença significante $(\mathrm{p}=0,8)$.

Na Tabela 1, são apresentados os resultados das comparações entre o diagnóstico histopatológico e a carga viral do HIV, estratificados pelo momento da quantificação da carga viral, em relação à data da realização da biópsia do colo uterino. Não houve associação significante entre a presença da SIL e a quantificação da carga viral nos seis meses mais próximos da data da biópsia (OR: 4,17; IC 95\% : 0,61-35,55), ou quando essa quantificação foi realizada anteriormente a esses seis meses (OR: 2,67; IC 95\% : 0,62$11,75)$. Quando não foi considerado o momento de quantificação da carga viral em relação à biópsia, foi encontrado resultado significante (OR: 3,13; IC 95\% : 1,05-9,53; $p=0,02)$. Também foi observada associação significante quando se realizou o ajustamento pelo momento em que foi quantificada a carga viral no valor maior que 400 cópias / $\mathrm{mL}$ para a presença de SIL. Essa associação foi verificada pelo odds ratio de Mantel Haenszel (OR: 3, 17; IC 95\% : 1,02-9,93). 
Tabela 1 - Relação entre o resultado histopatológico das biópsias de colo uterino e a quantificação da carga viral do HIV, obtida antes da realização da biópsia. Comparação entre quantificações com menos ou mais de 6 meses.

\begin{tabular}{|c|c|c|c|c|c|c|}
\hline $\begin{array}{l}\text { Tempo } \\
\text { (meses) }\end{array}$ & $\begin{array}{l}\text { Carga viral } \\
\text { (cópias } / \mathrm{mL} \text { ) }\end{array}$ & $\begin{array}{c}\text { SIL } \\
\mathrm{n}(\%)\end{array}$ & $\begin{array}{l}\text { Não-SIL } \\
\mathrm{n}(\%)\end{array}$ & $\begin{array}{c}\text { OR } \\
\text { (IC 95\%) }\end{array}$ & $\begin{array}{c}\mathrm{OR}_{\mathrm{MH}} \\
\text { (IC } 95 \% \text { ) }\end{array}$ & $\begin{array}{c}\chi^{2}{ }_{\mathrm{MH}} \\
\text { (valor - p) }\end{array}$ \\
\hline \multirow[t]{3}{*}{$\leq 6$} & $>400$ & $10(45,5)$ & $12(54,5)$ & 4,17 & & \\
\hline & $\leq 400$ & $2(16,7)$ & $10(83,3)$ & $(0,61-35,55)$ & & \\
\hline & & & & & 3,17 & 3,91 \\
\hline \multirow[t]{2}{*}{$>6$} & $>400$ & $22(66,7)$ & $11(33,3)$ & 2,67 & $(1,02-9,93)$ & $(0,048)$ \\
\hline & $\leq 400$ & $6(42,9)$ & $8(57,1)$ & $(0,62-11,75)$ & & \\
\hline
\end{tabular}

SIL - lesão intra-epitelial cervical

IC - intervalo de confiança

$\mathrm{OR}$ - odds ratio

$\mathrm{OR}_{\mathrm{MH}}$ - odds ratio de Mantel-Haenszel

$\chi^{2}{ }_{M H}-\chi^{2}$ de Mantel-Haenszel

Comparação semelhante foi realizada entre a presença da SIL e a contagem de linfócitos $\mathrm{T}$ $\mathrm{CD}^{+}$, não tendo sido encontrada associação sig- nificante entre essas variáveis, verificada pelo odds ratio de Mantel-Haenszel (OR: 1,19; IC 95\% : 0,54-2,64) (Tabela 2).

Tabela 2 - Relação entre o resultado histopatológico das biópsias de colo uterino com a contagem de linfócitos T CD4+ obtida antes da realização da biópsia. Comparação entre quantificações com menos ou mais de 6 meses.

\begin{tabular}{|c|c|c|c|c|c|c|}
\hline $\begin{array}{c}\text { Tempo } \\
\text { (meses) }\end{array}$ & $\begin{array}{c}\text { Linfócitos T CD4 } \\
\text { (células } / \mathrm{mm}^{3} \text { ) }\end{array}$ & $\begin{array}{l}\text { SIL } \\
\mathrm{n}(\%)\end{array}$ & $\begin{array}{c}\text { Não-SIL } \\
\mathrm{n}(\%)\end{array}$ & $\begin{array}{c}\text { OR } \\
\text { (IC 95\%) }\end{array}$ & $\begin{array}{l}\mathrm{OR}_{\mathrm{MH}} \\
\text { (IC } 95 \% \text { ) }\end{array}$ & $\begin{array}{c}\chi^{2}{ }_{M H} \\
\text { (valor - p) }\end{array}$ \\
\hline \multirow[t]{3}{*}{$\leq 6$} & $<200$ & $15(60,0)$ & $10(40,0)$ & 2,50 & & \\
\hline & $\geq 200$ & $6(37,5)$ & $10(62,5)$ & $(0,58-11,21)$ & & \\
\hline & & & & & 1,19 & 0,08 \\
\hline \multirow[t]{2}{*}{$>6$} & $<200$ & $13(48,1)$ & $14(51,9)$ & 0,82 & $(0,54-2,64)$ & $(0,779)$ \\
\hline & $\geq 200$ & $35(53,0)$ & $31(47,0)$ & $(0,31-2,21)$ & & \\
\hline
\end{tabular}

SIL - lesão intra-epitelial cervical

IC - intervalo de confiança

$\mathrm{OR}$ - odds ratio

$\mathrm{OR}_{\mathrm{MH}}-$ odds ratio de Mantel-Haenszel

$\chi^{2}{ }_{\mathrm{MH}}-\chi^{2}$ de Mantel-Haenszel

Realizou-se a análise de variância para a carga viral do HIV e a contagem de linfócitos $\mathrm{T}$ $\mathrm{CD}^{+}$. Comparando-se o valor médio da contagem dos linfócitos $\mathrm{T} \mathrm{CD}^{+}$e a presença ou ausência da SIL, não foram encontradas diferenças significantes $(p=0,7042)$. Comparando-se a mediana da carga viral do HIV e a presença ou ausência de SIL também não foram encontradas diferenças significantes $(p=0,1174)$.

\section{Discussão}

A literatura é controversa quanto aos fatores que podem influenciar a evolução da lesão intra-epitelial cervical em mulheres soropositivas para o HIV. Entre os fatores destacam-se a presença do HPV, o uso de anti-retrovirais, principalmente a HAART, e os marcadores de progressão da infecção pelo HIV. Embora o HPV não tenha sido motivo deste estudo, há relatos que a sua alta prevalência e, até mesmo, sua persistência na cérvice uterina em mulheres HIV-positivas, pode interferir ou não na presença, gravidade, progressão ou regressão das lesões cervicais em mulheres usando anti-retrovirais ${ }^{22,23}$. Observamos que a maioria dos estudos utiliza, para realizar suas comparações, resultados de citologia ${ }^{17,22-26}$, embora alguns mencionem que a biópsia foi realizada. Há um estudo que não informa se utilizou resultados do exame citológico ou histopatológico ${ }^{27}$.

Embora os cortes analisados neste estudo para a contagem de linfócitos $\mathrm{T} \mathrm{CD} 4^{+}$tenham sido diferentes dos realizados por Coelho et al. ${ }^{17}$ (basearam-se na classificação da infecção pelo HIV, segundo as recomendações do $\mathrm{CDC}$ ), em ambos os estudos não foram encontradas evidências de associação entre a baixa contagem de linfócitos $\mathrm{T}$ $\mathrm{CD}^{+}$e a presença da SIL. Esses achados contra- 
riam os de Palefsky et al. ${ }^{24}$ e Delmas et al. ${ }^{25}$ Embora esses estudos tenham avaliado a incidência de SIL em mulheres HIV-positivas, os resultados indicaram ser maior o risco de infecção pelo HPV e SIL (na citologia), em pacientes com contagem de linfócitos T $\mathrm{CD}^{+}$inferior a 200 células $/ \mathrm{mm}^{3}$. Os resultados de um dos estudos sugerem que pode haver efeito protetor da terapia anti-retroviral para a ocorrência de SIL em mulheres infectadas pelo HIV, embora o uso regular da medicação não tenha sido avaliado ${ }^{25}$. Entretanto, observa-se que ainda não há entendimento suficiente sobre os mecanismos pelos quais a imunodeficiência decorrente da infecção pelo HIV aumenta o risco de aparecimento da SIL.

$O$ achado quase significante $(p \cong 0,06)$ de aumento do risco para SIL com a elevação da carga viral, quantificada antes da realização da biópsia, sugere provável deficiência no tamanho da amostra. Nossa hipótese é que poderemos encontrar associação significante aumentando o número de pacientes.

Quando avaliamos os dois diferentes tempos em que foi quantificada a carga viral do HIV, antes da realização da biópsia do colo uterino, não encontramos associação significante. Entretanto, houve associação significante entre carga viral e SIL, quando desconsideramos esse tempo (OR: 3,13; IC 95\% : 1,05-9,53; $p=0,02$ ) e, ao ajustarmos essas variáveis, também verificamos associação significante (OR: 3, 17; IC 95\% : 1,02-9,93; p=0,048). Esses achados indicam que o tempo da realização da quantificação da carga viral não pode ser considerado fator de confusão, nem de interação neste estudo, porque não interfere na associação entre carga viral e SIL. No entanto, observamos maior risco de ocorrência da SIL entre as pacientes que apresentaram carga viral maior de 400 cópias/ $\mathrm{mL}$. Embora o enfoque tenha sido diferente, esse achado é semelhante ao de Davis et al. ${ }^{3}$. Estes autores encontraram, na análise univariada, associação entre a alta carga viral do HIV com a presença da SIL na biópsia, mas este achado não foi confirmado pela regressão logística, o que indica que a diferença encontrada na análise univariada pode se dever a fator de confusão entre as variáveis.

Observamos que o valor mediano da carga viral do HIV e o valor médio da contagem de linfócitos $\mathrm{T} \mathrm{CD}^{+}$não influenciaram na presença da SIL. Sopracordevole et al. ${ }^{27}$ também não encontraram associação entre o valor médio da contagem de linfócitos $\mathrm{T} \mathrm{CD}^{+}$e a presença da SIL. No entanto, os achados de Cardillo et al. ${ }^{26}$ contrariam os mostrados neste estudo. Analisando a mediana da carga viral do HIV em pacientes com e sem anormalidades citológicas, concluíram que as pacientes com SIL tinham carga viral significantemente mais alta em relação àquelas com citologia normal (109.316 cópias / mL versus 41.602 cópias / $\mathrm{mL} ; \mathrm{p}=0,006)$.

Pode-se observar, portanto, que o tema ainda é controverso, sendo necessários estudos com maior número de pacientes para podermos estabelecer qual a verdadeira associação existente entre a contagem dos linfócitos $\mathrm{T} \mathrm{CD}^{+} \mathrm{e}$ a quantificação da carga viral do HIV na origem e progressão das SIL em mulheres soropositivas para o HIV. Concluímos que as pacientes com quantificação da carga viral do HIV maior que 400 cópias $/ \mathrm{mL}$, antes da realização da biópsia do colo uterino, apresentaram chance 3,17 vezes maior de apresentar SIL. Por sua vez, a contagem dos linfócitos T CD4 ${ }^{+}$não influencia o surgimento destas lesões.

\section{Referências}

1. Maiman M, Fruchter RG, Serur E, Remy JC, Feuer G, Boyce J. Human immunodeficiency virus infection and cervical neoplasia. Gynecol Oncol. 1990;38(3):377-82.

2. 1993 revised classification system for HIV infection and expanded surveillance case definition for AIDS among adolescents and adults. MMWR Recomm Rep. 1992;41(RR-17):1-19.

3. Davis AT, Chakraborty H, Flowers L, Mosunjac MB. Cervical dysplasia in women infected with the human immunodeficiency virus (HIV): a correlation with HIV viral load and CD4+ count. Gynecol Oncol. 2001;80(3):350-4.

4. Pautier P, Morice P, de Crevoisier R. HIV and uterine cervical cancer. Bull Cancer. 2003;90(5):399-404.

5. Suarez Rincon AE, Vazquez Valls E, Ramirez Rodriguez M, Montoya Fuentes H, Covarrubias Rodriguez ML, Sanchez Corona J. Squamous intraepithelial lesions in HIV seropositive females. Their frequency and association with cervical neoplasia risk factors. Ginecol Obstet Mex. 2003;71:32-43.

6. Bosch FX, Lorincz A, Munoz N, Meijer CJ, Shah KV. The causal relation between human papillomavirus and cervical cancer. J Clin Pathol. 2002;55(4):24465.

7. de Sanjosé S, Palefsky J. Cervical and anal HPV infections in HIV positive women and men. Virus Res. 2002;89(2):201-11.

8. Souza NST, Melo VH, Castro LPF. Diagnóstico da infecção pelo HIV em lesões do colo do útero em mulheres HIV positivas: acuidade da histopatologia. Rev Bras Ginecol Obstet. 2001;23(6):355-61. 
9. Heard I, Tassie JM, Schmitz V, Mandelbrot L, Kazatchkine MD, Orth G. Increased risk of cervical disease among human immunodeficiency virus-infected women with severe immunosuppression and high human papillomavirus load. Obstet Gynecol. 2000;96(3):403-9.

10.Rachid M, Schechter M. Manual de HIV/AIDS. $7^{\text {a }}$ ed. Rio de Janeiro: Revinter; 2003.

11.Levi JE, Kleter B, Quint WG, Fink MC, Canto CL, Matsubara R, et al. High prevalence of human papillomavirus (HPV) infections and high frequency of multiple HPV genotypes in human immunodeficiency virus-infected women in Brazil. J Clin Microbiol. 2002;40(9):3341-5.

12.Levi JE, Fernandes S, Tateno AF, Motta E, Lima LP, Eluf-Neto J, et al. Presence of multiple human papillomavirus types in cervical samples from HIVinfected women. Gynecol Oncol. 2004;92(1):225-31.

13. Ho DD. Viral counts count in HIV infection. Science. 1996;272(5265):1124-5.

14.Vernazza PL, Eron JJ, Fiscus SA, Cohen MS. Sexual transmission of HIV: infectiousness and prevention. AIDS. 1999;13(2):155-66.

15.Massad LS, Riester KA, Anastos KM, Fruchter RG, Palefsky JM, Burk RD, et al. Prevalence and predictors of squamous cell abnormalities in Papanicolaou smears from women infected with HIV-1. Women's Interagency HIV Study Group. J Acquir Immune Defic Syndr. 1999;21(1):33-41.

16.Minkoff H, Ahdieh L, Massad LS, Anastos K, Watts $\mathrm{DH}$, Melnick S, et al. The effect of highly active antiretroviral therapy on cervical cytologic changes associated with oncogenic HPV among HIV-infected women. AIDS. 2001;15(16):2157-64.

17. Coelho RA, Facundo MKF, Nogueira AL, Sakano CRSB, Ribalta JCL, Baracat EC. Relação entre diagnóstico citopatológico de neoplasia intraepitelial cervical e indices de células CD4+ e de carga viral em pacientes HIV-soropositivas. Rev Bras Ginecol Obstet. 2004;26(2):97-102.

18. Wright TC Jr, Ellerbrock TV, Chiasson MA, Van Devanter N, Sun XW. Cervical intraepithelial neo- plasia in women infected with human immunodeficiency virus: prevalence, risk factors, and validity of Papanicolaou smears. New York Cervical Disease Study. Obstet Gynecol. 1994;84(4):591-7.

19. Richart RM. Cervical intraepithelial neoplasia: a review. In: Sommers SC, editor. Pathology annual. New York: Appleton-Century-Crofts; 1973. p. 30128.

20.Armitage P, Berry G. Statistical methods in medical research. 2nd ed. Oxford: Blackwell Scientific; 1990.

21.Kahn HA, Sempos CT. Statistical methods in epidemiology. New York: Oxford University Press; 1989.

22.Heard I, Schmitz V, Costagliola D, Orth G, Kazatchkine MD. Early regression of cervical lesions in HIV-seropositive women receiving highly active antiretroviral therapy. AIDS. 1998;12(12):1459-64.

23.Lillo FB, Ferrari D, Veglia F, Origoni M, Grasso MA, Lodini S, et al. Human papillomavirus infection and associated cervical disease in human immunodeficiency virus-infected women: effect of highly active antiretroviral therapy. J Infect Dis. 2001;184(5):54751.

24.Palefsky JM, Minkoff H, Kalish LA, Levine A, Sacks HS, Garcia P, et al. Cervicovaginal human papillomavirus infection in human immunodeficiency virus-1 (HIV)-positive and high risk HIV-negative women. J Natl Cancer Inst. 1999;91(3):226-36.

25.Delmas MC, Larsen C, van Benthem B, Hamers FF, Bergeron C, Poyeda JD, et al. Cervical squamous intraepithelial lesions in HIV-infected women: prevalence, incidence and regression. European Study Group on Natural History of HIV Infection in Women. AIDS. 2000;14(12):1775-84.

26.Cardillo M, Hagan R, Abadi J, Abadi MA. CD4 T- cell count, viral load, and squamous intraepithelial lesions in women infected with the human immunodeficiency virus. Cancer. 2001;93(2):111-4.

27.Sopracordevole F, Campagnutta E, Parin A, Vaccher E, Volpe R, Scarabelli C. Squamous intraepithelial cervical lesions in human immunodeficiency virusseropositive women. J Reprod Med. 1996;41(8):58690. 